\title{
ENTRE MODULACIONES DE AFECTO Y AUTORIDAD EN EPISODIOS DE LA HISTORIA DE LA EDUCACIÓN CHILENA (C.1820-C.1950).
}

\author{
Pablo Toro-Blanco ${ }^{1}$
}

\section{RESUMEN}

Este artículo, que se inscribe en el marco de la historia de las emociones en la educación, busca presentar distintas articulaciones entre los conceptos de afecto y autoridad en diferentes períodos de la historia de la educación chilena. A través del análisis sobre el discurso de teóricos, autoridades, profesores y estudiantes, se lleva a cabo un recorrido que permite apreciar el tránsito desde formas de autoridad basadas en el castigo físico y el discurso moral-religioso hacia estilos de relaciones interpersonales asentadas sobre mayores componentes afectivos y discursos de matriz psicológica. La perspectiva de transformaciones, es importante señalarlo, no se interpreta en términos lineales ni teleológicos, sino que se postula la contingencia histórica de las formas de articulación de vínculos entre el par polar afecto-autoridad.

palabras claves: educación chilena, historia de las emociones, autoridad, afecto.

${ }^{1}$ Universidad Alberto Hurtado (UAH), Santiago, Chile. 


\section{MODULAÇÕES DA AFETO E DA AUTORIDADE NOS EPISODES DA HISTÓRIA DA EDUCAÇÃO CHILEna (C.1820-C.1950).}

\section{RESUMO:}

Este artigo, que se enquadra no âmbito da história das emoções na educação, tem como objetivo apresentar diferentes articulações entre os conceitos de afeto e autoridade em diferentes períodos da história da educação chilena. Através da análise sobre o discurso dos teóricos, autoridades, professores e alunos, é possível perceber o trânsito de formas de autoridade baseadas na punição física e o discurso moral-religioso para estilos de relações interpessoais se estabeleceram na matriz psicológica e discursos com mais componentes afetivos. Transformações de perspectiva, é importante salientar, não são interpretadas em termos lineares ou teleológicos, eles se aplicam a contingência de formas históricas de articulação das ligações entre o par polar afeto-autoridade.

palavras-chave: educação chilena, história das emoções, autoridade, afeto.

\section{MODULATIONS OF AFFECTION AND AUTHORITY IN EPISODES IN THE HISTORY OF CHILEAN EDUCATION (C.1820-C.1950).}

\section{ABSTRACT:}

This article, which falls within the framework of the history of emotions in education, aims to present different articulations between the concepts of affection and authority in different periods of the history of Chilean education. Through the analysis on the discourse of theorists, authorities, teachers and students, it sheds lights on the transit from forms of authority based on physical punishment and moral-religious speech towards styles of interpersonal relations settled on psychological matrix speeches and more affective components. These transformations, it is important to point out it, are not interpreted in a linear or teleological way, since they are built upon the contingency of historical forms of articulation of links between the polar pair affection-authority.

keywords: chilean education, history of emotions, authority, affection

\section{ENTRE AFFECT ET AUTORITE: MODULATIONS AU COURS DE DIFFERENTS MOMENTS DE L'HISTOIRE DE L'EDUCATION CHILIENNE (C. 1820-C. 1950)}

\section{RÉSUMÉ:}

Cet article, qui s'inscrit dans le cadre de l'histoire des émotions dans l'éducation, a pour but de présenter les différentes articulations entre les concepts d'affection et d'autorité à différentes périodes de l'histoire de l'éducation chilienne. Grâce à l'analyse sur le discours des théoriciens, les autorités, les enseignants et les étudiants, il est possible voir le transit de formes d'autorité basée sur les châtiments corporels et le discours moral-religieuse vers les styles de relations interpersonnelles s'installe sur le discours de matrice psychologique et affectifs plus de 
composants. Transformations du point de vue, il est important de souligner il, il n'est pas interprété en termes linéaires ou téléologique, elles s'appliquent à la contingence des formes historiques de l'articulation des liens entre la paire polaire affection-autorité.

Mots-clés: education chilien, histoire de l'émotions, autorité, affection 


\section{INTRODUCCIÓN: DOS VOCES DISTANTES.}

En un artículo de prensa publicado en abril de 1856, atribuido al agudo periodista chileno Manuel Blanco Cuartín (1822-1890) se recordaba con ira cómo funcionaba la escuela de las primeras décadas del siglo XIX. La experiencia sufriente del castigo cotidiano y la sensación de dolor y desagrado, un quemante rescoldo que no se apagaba después de varios años de haber abandonado las aulas, eran parte de la memoria de generaciones recientes. Uno de los mayores reproches se formulaba contra la conducta de los profesores con sus estudiantes:

¿No era pues la escuela de nuestros antepasados una verdadera arena romana, en que la fiera del pedagogo se gozaba, a la manera de César Augusto, en las lamentaciones y gemidos de los infelices latinistas en ciernes? ¿Y con este fatal sistema de educación, podía esperarse una juventud delicada, pudorosa y llena de ideas generosas y grandes? ¿El castigo del amigo, no debería sembrar desde temprano en el corazón de los jóvenes, la semilla de funestos rencores, cuyas consecuencias tarde o temprano refluirían, sin duda, en perjuicio de la sociedad entera? (BLANCO CUARTÍN, 1856, p. 3)

Casi un siglo después, un estudiante del principal establecimiento secundario de la educación pública chilena, presentaba una valoración afectiva muy distinta respecto a uno de sus profesores, a quien le concedía la característica de cercanía que lo identificaba como « gente de la casa » :

No se piense, sin embargo, que Don Luis sea un profesor temible, de esos que hacen cortar la voz y la respiración al dárseles la lección. Tal «virtud» antipedagógica y, por consiguiente antagónica con la calidad de maestro, no es de él. Muy por el contrario. Los niños, que saben de psicología práctica y de la apreciación de los valores humanos sin necesidad de conocer a James, a Malapert o a Janet, depositan en Don Luis su simpatía y confianza (A.M.P., 1950 , p. 12)

Las dos voces contrastantes aquí presentadas, distantes y distintas, nos 
han de servir de pivotes testimoniales para marcar los extremos de un trayecto al cual nos interesa dedicar las siguientes páginas : el camino recorrido por afecto y autoridad en las relaciones al interior de las escuelas, principalmente del nivel secundario, durante cerca de un siglo en el sistema educacional chileno. La ruta trazada entre la memoria doliente presentada por Blanco Cuartín respecto a esos profesores-verdugos y la experiencia confiada y plena de simpatía del estudiante de 1950 y sus compañeros con su profesor de historia difícilmente puede concebirse como un camino rectilíneo, ascendente y carente de curvas y accidentes. Lo visualizamos, más bien, como un trayecto en que dos de los términos que privilegiamos analíticamente en estas páginas como constructores de la relación profesor-estudiante (afecto y autoridad) describen trayectorias múltiples, se acercan entre sí o se repelen ; se subordinan el uno al otro o dialogan.

En función de lo propuesto, este artículo se inicia con un breve encuadre historiográfico y conceptual, en el cual interesa inscribir el conjunto de la reflexión aquí sostenida en el marco de la historia de las emociones en la educación y, además, delimitar la apropiación que haremos de los términos en uso. Posteriormente, se procede a caracterizar, muy sintéticamente, algunos episodios de modulaciones de los vínculos entre afecto y autoridad en distintos ciclos de la historia de la educación chilena.

\section{AFECTO, AUTORIDAD: BREVES DELIMITACIONES.}

La historia de la educación, siguiendo un movimiento general de la historiografía, ha tendido recientemente a relevar dimensiones de la cotidianeidad escolar que rebasan los límites frecuentemente visitados de las políticas educacionales, los sistemas organizativos o el currículo. En consonancia con ello, debido a las preocupaciones derivadas del «giro afectivo » experimentado por las ciencias sociales y humanas, se ha ampliado la 
agenda de investigación del pasado de la educación (MAHAMUD, 2012, p. 1-3). Así, se le ha concedido carta de ciudadanía a las dimensiones afectivas y emocionales de las experiencias escolares pretéritas. Especialmente importante ha sido el esfuerzo por develar lo que se podría entender como las gramáticas de la cotidianeidad educacional, o sea, los supuestos implícitos bajo los cuales se desenvuelven sus diferentes actores, en una lógica cercana inicialmente a los intereses de los «estudios de gubernamentalidad », de matriz foucaltiana (SOBE, 2012, p. 691-692). Siendo el acto educativo una relación marcada históricamente por el desbalance de poder entre los sujetos involucrados, cobra especial importancia comprender las características cambiantes que ha adquirido su dimensión convivencial, sobre todo desde un contexto como el actual, en el que una miríada de disciplinas (la principal de ellas, la psicología) han establecido como hecho de la causa los lazos estructurales que existen entre emoción y aprendizaje.

El reconocimiento de los factores emocionales como aspectos cruciales en el cumplimiento de las tareas de la escolarización (generalizado en las ciencias de la educación durante el siglo XX) tiene que ver, ciertamente, con la propia transformación de aquéllas. Tal como cualquier producto cultural (y, por ende, histórico), en el análisis diacrónico de la escuela es posible discernir tanto elementos estructuradores, que le dan soporte a través del tiempo, como también giros que, con mayor o menor dramatismo, la reconfiguran. En función de ello resulta posible apreciar y comparar, para nuestros efectos, lo que entendemos como modulaciones de afecto y autoridad en distintos episodios de la educación chilena a través de la etapa republicana. Tenemos en consideración dos puntos de apoyo con los cuales pretendemos que nuestra perspectiva se enriquezca: el primero, fiel a un enfoque hermenéutico que reconoce la situación desde la que hablamos, nos sitúa en una mirada a lo que podríamos definir como el «punto de llegada » del proceso de reconfiguración de las relaciones entre afecto y autoridad, a propósito del estado reciente de la cuestión, en lo que a la dimensión emocional de lo educativo se refiere. En segundo lugar, nos interesa introducir una observación de carácter conceptual, 
relacionada con la «noción de lenguaje» de la educación, siguiendo la propuesta del reputado académico suizo Daniel Tröhler.

En relación al primer insumo recién señalado, cabe establecer que los paradigmas educativos y psicológicos recientes respecto a la formación emocional de los estudiantes presentan un amplio repertorio de formulaciones. No obstante, un elemento que les es común es el rol que le conceden a los propios estudiantes en el descubrimiento y gestión de sus propias emociones, lo que tiene consecuencias predecibles respecto a las modulaciones contemporáneas de afecto y autoridad en el mundo escolar. En un texto académico reciente, en el que se pasa revista a la evolución de la psicología educacional a lo largo del siglo XX, se llega a la enunciación del modelo de estudiante deseable actualmente, bajo la figura de la «Triple E»: un sujeto que se construye, desde el aprendizaje con centro en su propia persona, como expresivo, emprendedor y empoderado(MARTIN \& McLELLAN, 2013, p. VIII). Esta figura se encuentra íntimamente incardinada con las necesidades del paradigma económico globalizador en curso y ha logrado expandirse planetariamente, en diferentes niveles de velocidad y profundidad, acompañando las lógicas generales de la educación como proceso en el que los sistemas nacionales han tendido, debido al debilitamiento creciente de las fronteras del Estado-Nación, a interactuar de modo cada vez más sincronizado con los modelos de escala global, dando cuenta de lo que Francisco Ramírez y John Meyer han rotulado como tendencias al «isomorfismo educacional»(RAMÍREZ \& MEYER, 2012, p. 108).

Respecto al segundo elemento que consideramos, Daniel Tröhler identifica lo que él denomina como lenguajes de la educación, o sea, "modos o modalidades distinguibles de pensar, hablar o escribir sobre la educación" (TRÖHLER, 2013, p. 23). Dichos lenguajes constituirían una articulación prácticamente tácita, una suerte de gramática en la que se desenvuelven los protagonistas de la vida escolar, muchas veces sin notarlo aunque, por ser finalmente un proceso histórico, modificándola con sus discursos y prácticas. 
Dos matrices de lenguajes de la educación derivadas del proceso de la Reforma a partir del siglo XVI (en el que la escolarización cobró singular importancia asociada a la alfabetización como insumo salvífico), han tenido singular importancia, de acuerdo a la argumentación de Tröhler, para fundar y legitimar la construcción de los sistemas nacionales de educación. La primera de ellas, tributaria del calvinismo, estableció una relación estrecha entre aprendizaje, socialización, experimentación y se expresó en los orígenes del autogobierno republicano que florecería en suelo americano en el siglo XVIII con la independencia de los Estados Unidos, perviviendo mediante las corrientes pragmatistas y democratizadoras de la educación representadas, en el paso del siglo XIX al XX, por John Dewey. Por su parte, la segunda corriente principal, asociada primordialmente a la matriz luterana, puso su foco en la búsqueda de la virtud y perfección interior (bildung) y relegó a un segundo plano la vinculación más estrecha entre aprendizaje y sociedad, lo que implicó que tuviera un mayor grado de apego al reforzamiento de prácticas autoritarias. En lo que a nuestro tema concierne, esta figura interpretativa resulta interesante como herramienta para analizar el caso chileno puesto que, a grandes rasgos, durante parte importante del desarrollo de su sistema educacional Chile adoptó referentes europeos como modelos a seguir, los que analíticamente podrían ser mirados desde la lógica de sus lenguajes educativos. Así, en los inicios del sistema educacional republicano el discurso legitimador era deudor, esencialmente, de la tradición pedagógica republicana francesa. Dicho lenguaje educativo ponía el énfasis en los conocimientos útiles y racionales y en la dimensión pública y política que estaban en su núcleo, por lo que el objetivo de la educación era no tanto la virtud interior como sí el conocimiento verificable y la orientación hacia lo público(TRÖHLER, 2013, p. 36). Dicho lenguaje educativo, mediado por las nociones de orden y autoridad prevalentes en la cultura de matriz colonial-religiosa chilena, dio como fruto una síntesis ad-hoc entre ilustración y catolicismo, funcional a los intereses de los grupos sociales que fueron tutores de la ruptura con España y del establecimiento del nuevo orden republicano, visión pragmática que pudo expresarse sintéticamente en la 
continuidad colonial (por lo religioso) y la novedad ilustrada-republicana (por lo científico y técnico) del proyecto del Instituto Nacional como establecimiento que sería el modelo de desarrollo del naciente sistema(SERRANO, PONCE DE LEÓN \& RENGIFO, 2012, p. 62-68).

No obstante, a partir de la reforma de inspiración alemana al sistema educacional chileno, en el último cuarto del siglo XIX, sería posible detectar una transformación respecto al lenguaje educativo de base que sustentaría a la educación chilena. De tal manera, la introducción del referente alemán (tributario de la segunda matriz de lenguaje educativo) habría implicado un giro hacia un paradigma expresado en la idea de bildung, esto es, formación integral de la personalidad del estudiante(CONEJEROS, 2015, p. 44-45). Dicha demanda (de profundidad más que centenaria en su formulación original en suelo alemán) sería concurrente históricamente con los avances de la psicología y la educación en su camino de constitución como campos de saber, lo que plantearía interesantes negociaciones entre una matriz de lenguaje con fuerte apoyo en la noción de autoridad, por un lado, y los prolegómenos del « giro paidológico » al que se asistiría durante el siglo XX, por otra parte.

Ya señalados los dos elementos que consideramos que ayudan a situar con mayor claridad nuestra propuesta interpretativa, corresponde abordar la delimitación de los dos términos que se encuentran en el centro de ella: afecto y autoridad. Al respecto, se hace necesaria una prevención inicial: en lo que sigue, ambos términos han sido objeto de una selección y acotamiento semántico indispensable. Siendo conceptos polisémicos, que reconocen domicilio en muy diversos escenarios interpretativos y disciplinas académicas, el recorte que se propone en estas páginas tiene como propósito pensarlos desde la perspectiva de la educación, introduciéndolos como variables que parecerían, en principio, constituir los extremos de un arco de relaciones posibles en el vínculo profesores-estudiantes.

El problema de la definición del afecto como objeto de análisis requiere algunas precisiones iniciales, de modo de evitar las consecuencias a las que 
puede arrojar la polisemia del término. En estricto sentido, al interior de los estudios históricos sobre emociones, terreno en el que se inscribe este texto, el término afecto se eleva como uno de los que disputa las preferencias para dar cuenta del campo general de análisis. Así, por ejemplo, Jan Plamper, en el contexto de su defensa del término emoción como rótulo anti nominalista que hace viable el desarrollo del área de estudio, da cuenta de cómo el vocablo afecto se ha erigido en un término empleado por varios investigadores que, atentos a los avances de las neurociencias, han relevado su sentido de emoción inconsciente, pre-lingüística y meramente física(PLAMPER, 2012, p. 11-12). Con todo, en esta propuesta no abordaremos los alcances mayores de esa discusión sobre la diferencia entre emoción y afecto y sí delimitaremos a éste en su significado más filial, vinculatorio, expresado en relaciones interpersonales, que se aproxima más a la idea de cariño. En este sentido, pensando en los episodios iniciales a los que se presta atención en estas páginas, la definición canónica de la Real Academia de la Lengua, en su Diccionario de 1817, indicaba que el afecto, en su primera acepción, correspondía a « cualquiera de las pasiones del ánimo como de ira, amor, odio, etc. Se dice más particularmente del amor o cariño »(RAE, 1817 , p. 22).

Dicha conceptualización respecto al afecto experimentó cambios, sumas y restas de contenido a lo largo de los siglo XIX y XX pero no eliminó como referencia semántica principal la idea de que el afecto tiene el sentido de una pulsión que se asocia al cariño y, por ende, a un dominio benéfico para quien está sometido a su imperio. Así, en un texto para formación de profesores elaborado por un destacado docente chileno hacia inicios de la década de 1930, se caracterizaba al afecto de la siguiente manera:

No deben confundirse los afectos con las pasiones. Los afectos proceden del sentimiento, no son tan profundos y expresan particularmente el bienestar físico, en tanto que las pasiones ejercen presión irresistible sobre los instintos e inclinaciones como una afección fatídica del ánimo. Los afectos son signo de felicidad; las pasiones un fardo de martirio; los afectos son vivos, pero de efecto momentáneo; las pasiones son crónicas, de tono frío e inexorable 
(MUÑOZ HERMOSILLA, 1931, p. 270)

Por ende, nuestro recorte semántico pone el énfasis en el afecto como una emoción que vincula, idealmente de modo biunívoco, a profesores y estudiantes en términos que se reputan como positivos, de cercanía y cariño filial. Ahora bien, en lo que respecta a la idea de autoridad nos encontramos con similar escenario: una pluralidad de posibles comprensiones. Recurriendo al mismo diccionario anterior, la autoridad es definida como « el carácter o representación que tiene alguna persona por su empleo, mérito o nacimiento»(RAE, 1817 , p. 106). Tal carácter remitía a la potestad, o sea, el dominio, poder o jurisdicción de una persona sobre otra. De modo tal que, en suma, la autoridad tiene su apoyo esencial en la noción de poder y, por ende, en la disparidad. En función de ella, es fácilmente deducible el peso histórico que esta noción ha jugado en el contexto de las relaciones educacionales. Hacia fines del siglo XIX el sentido de autoridad construida desde la apelación a la legitimidad y necesidad del poder adulto era presentado en un manual de pedagogía premiado por el Gobierno chileno:

\footnotetext{
El educador restringe su libertad personal y exige que se someta al régimen escolar, el emblema del futuro régimen social, donde rigen como bases solo las reglas que se refieren al bienestar general de la comunidad. El niño que como alumno pertenece a un todo, debe acondicionar sus actos de modo que correspondan a lo que le prescribe la ley fundamental; y la educación en la escuela, tomada en sentido limitado, consiste justamente en acostumbrar al alumno a prescindir de su propia voluntad, y hacer lugar a la de su autoridad, es decir, a la del maestro. Si así lo hace, obedece (ROSSIG, 1896, p. 32).
}

Nos resulta propicio, al interior de este contexto semántico, considerar posibles dimensiones emocionales relacionadas con la autoridad. El filósofo Richard Sennett ha abierto una amplia y fructífera senda para ello. En los inicios de su proyecto intelectual destinado a dar cuenta de los vínculos emocionales de la sociedad moderna, Sennett identifica como principales a los 
siguientes: autoridad, fraternidad, soledad y ritualidad (SENNETT, 1982, p. 17). Aludiendo al primero de ellos, el autor establece una dimensión que creemos pertinente para pensar a la autoridad en términos emocionales. La autoridad tiene, entre sus potencialidades, las capacidad de brindar seguridad, arraigo. En su asimetría, expresión de poder de unos sobre otros, recoge el mandato de desafiar la incertidumbre:

uno de los significados de un término latino de autoridad, el de auctor, es el de que la autoridad puede dar garantías a otros acerca del valor duradero de lo que ella hace. Es algo sólido. Pero el vinculo social no es más ucrónico que el personal. Es histórico, no puede evitar cambiar. La fuerza que simbolizan esos monumentos de la autoridad constituye un desafío a la historia, un desafío al tiempo (SENNETT, 1982, p. 26).

Ese sentido emocionalmente constructivo de la autoridad, con todo, no parece haber sido el que ha tenido mayor relieve a través de la evolución de las relaciones educacionales. En lo que sigue, nos abocaremos a distinguir sucintamente algunas de sus modulaciones específicas, en diálogo con las del afecto, en una mirada panorámica a la educación chilena.

\section{EPISODIOS FUNDACIONALES : AFECTOS CONTROLADOS Y AUTORIDAD EXPANDIDA.}

Describiendo el ambiente educacional de las primeras décadas después de la independencia de Chile, lograda en 1818, un historiador señalaba que predominaba en la experiencia estudiantil un sentido de distancia frente a sus profesores: «se anidaba en sus corazones una sorda antipatía contra preceptores que usaban para todo la opresión, las reprensiones, el chicote, como si jamás hubieran conocido la infantil ingenuidad ni la expansión personal ni la espontaneidad »(MUÑNZ HERMOSILLA, 1918 , p. 101). Difícilmente el afecto, en los términos que ya hemos delimitado, podía emerger como una emoción 
predominante en las aulas. Ello era congruente, a su vez, con discursos y prácticas en las cuales se estaba recién abriendo paso más claramente, conforme se difundían textos pedagógicos que brindaban creciente atención a las características personales y pulsiones íntimas de los estudiantes como factores relevantes (posteriormente, indispensables) para el aprendizaje.

La configuración del campo pedagógico en Chile estaba en sus tímidos primeros balbuceos $\mathrm{y}$, por ende, matrices de análisis provenientes de la tradición religiosa mantenían un peso relativo importante en la producción de discurso sobre cómo enseñar y en qué consistía la naturaleza de la educación. Una muestra de estas concepciones tempranas puede ser el primer libro para la enseñanza en las escuelas de Santiago que, bajo el formato catequístico, en 1816 presentaba una descripción de la naturaleza humana que sustentaba el binario razón-pasión:

La vida racional y moral es necesaria para el buen arreglo de la animal, porque el concierto de ambas conduce a la perfecta bienaventuranza del hombre: el entendimiento es su guía y no teniendo en sí total cierto conocimiento de lo bueno y de lo justo, es obligado a buscarlo en la moral de la naturaleza y de la religión, y en las demás ciencias, que son fuentes de las reglas de las costumbres. La voluntad determina al hombre a ser bueno o malo, según fuere conforme, o contraria a su fin, que es la perfecta bienaventuranza (REYES, 1816, p. 169)

En dicho escenario conceptual se entendía que los afectos (en su acepción amplia de pasiones del alma) eran una expresión de una naturaleza a domeñar con la voluntad y el entendimiento. Para ello resultaba de extrema necesidad la labor pastoral de los preceptores, en el contexto restringido de la escuela, y de los adultos, en el campo general de la vida. Por eso es que era un deber de los hombres con sus semejantes, de acuerdo a lo que les enseñaba el catecismo citado a los estudiantes, «corregir y castigar los jueces a sus súbditos; los padres, tutores, y maestros a sus hijos, pupilos y discípulos, cada uno según su potestad y a proporción de las culpas, y entre iguales, e independientes amonestándose por modo de corrección fraterna»(REYES, 1816, p. 150). Esta 
noción, de matriz religiosa, reforzaba la necesidad de la autoridad (potestad) y no era, sin embargo, la única fuente de inspiración que circulaba en los primeros años de vida independiente para promover una educación escasamente atenta a discutir el afecto pero sí a priorizar la autoridad. Por razones parcialmente distintas, pese a su común preocupación original por el papel socializador de la religión que podía cumplir la escuela, en la década de 1820 tuvo su mayor protagonismo en Chile la enseñanza mutua o método de Lancaster, llegando a convertirse momentáneamente en la doctrina educativa oficial del Estado.

El sistema de enseñanza mutua o lancasteriano ofrecía a las nuevas autoridades republicanas la promesa de poder cubrir con el manto de la instrucción a una mayor cantidad de estudiantes sin depender de un sistema ampliado de formación docente, problema difícilmente abordable en los primeros años de independencia. Las resonancias fabriles y castrenses del método debían, inevitablemente, reforzar el perfil de autoridad del profesor. De hecho, se establecía una suerte de continuidad simbólica entre el púlpito religioso y la tarima desde la cual el preceptor vigilaba y dirigía el desempeño de sus masivas clases. La autoridad, en su expresión de mando, se ejecutaba apelando al dominio de los sentidos y los cuerpos. Así, "a una señal que el maestro daba con el pito o la campanilla, los alumnos pasaban de los semicírculos a las mesas, o sea de la lectura a la escritura. Era una disciplina verdaderamente militar»(AMUNÁTEGUI SOLAR, 1895, p. 18).

Las décadas siguientes de la educación chilena fueron testimonio de cómo fueron emergiendo, de forma inorgánica y a diferente velocidad $\mathrm{y}$ profundidad, reflexiones acerca del papel de afecto y autoridad en los procesos de enseñanza. Hacia mediados de siglo se instalaba una discusión acerca de las características de los inspectores no docentes en los liceos. Se mantenía, en el fondo, una aproximación binaria a los dominios de la razón y la pasión, pues se identificaba una exigencia diferenciada para los agentes pastorales de niños y jóvenes. Así, se sostenía que « el maestro se dirige a la inteligencia ; el inspector, 
al alma »(AMUNÁTEGUI SOLAR, 1891, p. 76). Esto reconocía un hecho interesante: la división de tareas propuestas, acorde al binario señalado, depositaba en los inspectores (que, en la época, frecuentemente eran simplemente estudiantes de cursos superiores) el cultivo de relaciones filiales y de trato cordial con los alumnos, estableciendo en ellos un atisbo de lo que sería la transición de una forma de autoridad tradicional (como poder) hacia un estilo distinto, con apertura a la dimensión de brindar seguridad y arraigo, de acuerdo a la acepción de la noción de autoridad que hemos privilegiado.

A partir de lo anterior, el ejercicio de la autoridad en escuelas y liceos durante buena parte del resto del siglo XIX puede ser caracterizado como una dialéctica entre la persistencia de un enfoque binario (y, en general, maniqueo) respecto a la índole infanto-juvenil, proveniente de las prácticas tradicionales y el influjo de perspectivas religiosas en clave de Cristiandad y, por otro lado, las apropiaciones teóricas y prácticas de la pedagogía como campo en formación, con los aportes de la psicología. De tal manera, podría decirse que la autoridad ejercida por los adultos en el espacio escolar transitó desde una comprensión de la naturaleza estudiantil como habitada por potentes pulsiones emocionales de difícil control, que debían ser domesticadas para erradicar de niños y jóvenes los trazos de su "mal espíritu", hacia una lectura más comprensiva de su índole, acorde a herramientas analíticas construidas desde un campo con pretensiones científicas. La noción de dicho "mal espíritu", no infrecuente en textos de profesores y rectores hacia mediados del siglo XIX para aludir a los estudiantes (especialmente aquellos más díscolos) nos parece evocadora de aquellas concepciones binarias a las que, de uno u otro modo, la teoría del control social o civilizatoria de las emociones ha adherido, expresada en lo que la historiadora Barbara Rosenwein denomina, desde una mirada crítica, como «modelo hidraúlico», o sea, que ellas son especies de fluidos internos a cada persona, que se encuentran en disposición de desbordarse y, por ende, que son reprimidos(ROSENWEIN, 2002, p. 834). A tal enfoque de interpretación de las emociones no le cabe, por cierto, una versión más propicia de autoridad que aquella que enfatiza su dimensión de poder y garantía de control. 
No obstante, como hemos tenido oportunidad de señalar en otro estudio, la noción de la autoridad en la relación profesor-alumno comenzará a transformarse con mayor intensidad hacia el último cuarto del siglo XIX(TOROBLANCO, p. 83-85). Muestra de ello es el estilo propuesto para la docencia que se deja ver en un manual de pedagogía de fines de siglo:

iNo sea el maestro siempre el «Júpiter tronante» con ceño adusto y severo; aprenda el arte de ser, a su debido tiempo, un niño entre los niños, que se alegra con ellos, que se entristece cuando ellos se entristecen, que juega con ellos y que les habla no como su superior, sino como un compañero de más edad y más experimentado! (ROSSIG, 1896, p. 24).

En las invocaciones pedagógicas de la última parte del siglo ya es posible notar que, a propósito de la expansión de la formación profesional de los docentes, la noción de autoridad prioritariamente entendida como mero ejercicio de potestad adulta y control de los extravíos de los niños y jóvenes víctimas de sus pulsiones emocionales comienza a experimentar matices significativos. Podríamos señalar que se asiste a un tiempo crucial de cambios, en que se mezclan agonizantes paradigmas previos y no terminan de definirse todavía los perfiles de qué se entenderá como un apropiado ejercicio de la autoridad, así como una comprensión del rol del afecto en el día a día escolar. Parte de esa mezcla de conceptos puede apreciarse en los consejos docentes de un experimentado profesor a sus nuevos colegas:

Debemos, pues, saber medirnos lo suficiente en las emociones que es menester provocar en los alumnos á fin de que atiendan y de fijarles en la memoria una lección. Si no atienden ni pueden recordar lo que comprendan, perderemos el trabajo de hacerles comprender. Pero como las emociones débiles bastan al objeto y estimulan la comprensión, á ellas debemos limitarnos prudentemente, teniendo en vista el aprovechamiento de los educandos. Nuestras reconvenciones, burlas y chistes deben ser ligeros, calculando no suscitar la hilaridad de la clase (LOIS, 1891, p. 475). 


\section{REFORMAS MODERNIZADORAS : AFECTOS EN EXPANSIÓN Y AUTORIDAD CONTROLADA.}

Los últimos lustros del siglo XIX y las primeras décadas del siglo XX fueron el escenario para que se reconfiguraran significativamente las relaciones entre afecto y autoridad en las escuelas y liceos de Chile. Más allá del discutible impacto autoritario que habría tenido la influencia pedagógica del reformismo alemán auspiciado por el Estado chileno, lo que resulta sumamente interesante es la paradoja que encerró, para efectos de la noción de autoridad en la vida escolar, este período: la profundidad del supuesto recrudecimiento de un estilo de autoridad docente como potestad y control, asociada a la influencia alemana, no parece haber tenido tanto impacto como sí lo tuvo la profesionalización del campo pedagógico, hecho que permitió el pronto desplazamiento de dicha influencia y la entrada de nuevas tendencias, principalmente vinculadas a la pedagogía norteamericana.

En este contexto es que aquellos indicios de reconfiguración de los términos de afecto y autoridad en las relaciones interpersonales en la escuela y el liceo comenzaron a generalizarse y marchar hacia su consagración como sentido común docente. Una muestra temprana puede encontrarse en las reflexiones de un pedagogo de aula, que aludía a un nuevo estilo de autoridad que debían poner en funcionamiento los profesores:

Cierto es que el maestro es para los niños una autoridad; pero ¿desde cuándo los superiores no pueden mezclarse con sus subalternos en momentos de gusto y expansión? Si esto fuera una verdad, resultaría que la mayor desgracia para el hombre sería ser una autoridad, puesto que por ese solo hecho quedaba aislado de entre sus semejantes y a mayor abundamiento cuando éstos gozan, cuando son felices. Que el respeto puede perderse, no es exacto; el respeto adquirido por la superioridad intelectual, física y moral es una noción que, bien adquirida por el niño y perfectamente valorizada, no se pierde nunca (VELASCO, 1903 , p. 169)

Estas inquietudes acerca de la autoridad marchaban en paralelo con la 
demanda que teóricos y docentes formulaban para que la relación entre profesores y estudiantes se modificara en términos emotivos, asunto que habría de demandar nuevas exigencias y habilidades a los docentes. De tal modo, el educador Carlos Fernández Peña proponía una reforma de la disciplina escolar dado que ella «debe dar al alumno amplia confianza para considerar al educador como consejero y amigo, a quien pueda interrogar sobre los problemas de la vida »(FERNÁNDEZ PEÑA, 1912 , p. 40).

Esta tendencia a asignar nuevo significado a autoridad y afecto se manifestaba a fines de la década de 1930, cuando se proponía «hacer de nuestros liceos de antaño, un tanto fríos, con poca vida interior, un ambiente de hogar, abundante en oportunidades para que la compleja naturaleza juvenil se despliegue en un amplio y profundo sentido social »(PIGA, 1935, p. 349). Ello era consistente con la definición de la tarea fundamental de los profesores jefes por el Reglamento General de Educación Secundaria, promulgado en 1928, que implicaría para los adultos « mantener una relación permanente y de confianza familiar con sus alumnos ; servirles de consejeros en sus dudas y vacilaciones, y ayudarlos a conseguir el mejor aprovechamiento de su permanencia en el colegio »(PALMA, 1928，p. 234). Profundizaciones de esta lógica estarían presentes luego en los procesos reformistas de la educación chilena ya en tiempos de la posguerra.

\section{BREVES REFLEXIONES FINALES.}

A inicios de la turbulenta década de 1960, período que puede ser entendido como un intenso episodio de reconfiguración de las relaciones entre infancia, juventud y mundo adulto, un estudiante de $6^{\circ}$ Año de Humanidades buscaba comprender qué le estaba pasando a su generación. El joven Ricardo Fürst Neumann, a través de una nota en la revista de su liceo, intentaba dar una explicación a lo que se diagnosticaba como un signo alarmante de los tiempos : el problema de la crisis de autoridad. Desplegando sus dotes de analista, el 
estudiante argumentaba que los nuevos balances entre el rol parental, las nuevas tendencias culturales y la expresión, crecientemente polémica, de la identidad juvenil se mezclaban para producir un resultado inestable : «es, por lo tanto, el medio ambiente uno de los factores principales de lo que se ha dado llamar «colerismo ». Se ha insistido mucho en que lo que más ha influido en esto es la pérdida de autoridad de los padres(...) »(FÜRST NEUMANN, 1961, p. 6). La conclusión del estudiante era consistente con los « pánicos morales » que se manifestaban en la sociedad chilena de la época, a propósito del proceso de construcción, no exento de problemas, de un nuevo pacto etario entre adultos y jóvenes, en el que el balance de la autoridad entre ellos, así como el contenido del afecto respectivo, sería sometido a profundas tensiones. De hecho, es plausible comprender la preocupación del estudiante Fürst Neumann como un producto de su coyuntura inmediata, dado que escribía sus impresiones no mucho tiempo después de un incidente criminal, de amplio impacto en los medios de comunicación de la época, que había gatillado una intensa discusión en la prensa respecto a qué estaba pasando con la juventud y su rechazo creciente a las formas tradicionales de autoridad (GONZÁLEZ CANGAS, 2011).

En el inicio de la ruta emprendida en estas breves páginas se asistía a dos escenas que, inscritas en el ámbito de la escolaridad chilena en tiempos distintos, compartían un núcleo principalmente emotivo, narrado desde la experiencia de los estudiantes. La primera, dejaba ver una agria crítica a la distancia existente en la relación entre profesores y alumnos, así como también denunciaba las consecuencias del desbalance de poder entre ambos actores. En esa circunstancia los niños y jóvenes aparecían más bien como objetos del despliegue del poder-autoridad de sus preceptores. Sin que se pudiera identificar la lógica específica de causa-efecto que detonaba el castigo ni siendo claro el perfil general de la intriga escolar, lo que quedaba claro era la existencia de un circuito de relaciones emotivas o un régimen emocional en que, presumiblemente, los términos del afecto y la autoridad-poder se articulaban principalmente por su distancia, su diferencia de sentido y canales de expresión que no convergían. El segundo episodio, por su parte, pareciera constituir una 
transformación de los lazos entre afecto y autoridad : un cambio producto de varias líneas paralelas tales como la acumulación de nuevos saberes de corte científico sobre la índole de los estudiantes y el reacomodo de los roles de tutoría adulta sobre el campo juvenil e infantil, conforme a la propia acumulación de agencia de y conocimiento sobre niños y jóvenes.

Con todo, la polaridad insinuada por los términos del trayecto escogido en estas páginas debe ser relativizada o, a lo menos, puesta en un paréntesis que la haga objeto de una reflexión más detenida, a nuestro entender. Deseando apartarnos de una noción teleológica del desarrollo histórico de las relaciones emocionales en la educación, nos parece necesario matizar aquellas perspectivas que, por ser excesivamente fieles a esquemas inspiradores (pero también generalizadores como, por ejemplo, la visión evolucionista de Norbert Elías), suelen interpretar de modo lineal los cambios en las relaciones de afecto y autoridad en la vida escolar, a la vez que construyen una oposición tajante, directamente proporcional en su intensidad a la lejanía desde el presente, entre paradigmas educativos tradicionales (que habrían estado centrados únicamente en la transmisión de conocimientos) e innovadores (que serían recientes, orientados a atender a una preterida dimensión emocional de los estudiantes). Así, por ejemplo, tenemos a la vista la necesidad de reconocer que la educación de las emociones no fue un componente totalmente extraño para la teoría educacional previa a la constitución científica del campo de la enseñanza en el último tercio del siglo XIX gracias a los aportes de la psicología. Esto, que ha quedado refrendado para el caso británico en un interesante estudio de Thomas Dixon, requiere todavía ser pertinentemente analizado en referencia a Chile, lo que abre un camino de investigación que merece ser emprendido en futuros estudios (DIXON, 2012). 


\section{REFERENCIAS BIBLIOGRÁFICAS}

A.M.P. “ «Gente de la Casa: Luis Alejandro », Boletín del Instituto Nacional, Año XV, nº36, Santiago de Chile, 1950.

AMUNÁTEGUI SOLAR, Domingo. El Instituto Nacional bajo los rectorados de don Manuel Montt, don Francisco Puente y don Antonio Varas (1835-1845), Santiago de Chile: Imprenta Cervantes, 1891.

AMUNÁTEGUI SOLAR, Domingo. El sistema de Lancaster en Chile y en otros países sudamericanos. Santiago de Chile: Imprenta Cervantes, 1895.

BLANCO CUARTÍN, Manuel. «Sistema correccional de las escuelas», El Ferrocarril, Santiago de Chile, 19 de abril de 1856.

CONEJEROS, Juan Pablo. De la francomanía al embrujo alemán. Alcances en torno al rol de los agentes mediatizadores en el proceso de transferencia cultural alemana en la educación chilena (1880-1910) en SILVA Benjamín (compilador) Historia Social de la Educación Chilena. Tomo I: instalación, auge y crisis de la reforma alemana. 1880 a 1920 . Agentes escolares. Santiago: Ediciones Universidad Tecnológica Metropolitana, 2015.

DIXON, Thomas. «Educating the emotions from Gradgrind to Goleman», Research Papers in Education, volumen 27, $\mathrm{n}^{\circ} 4$, Londres., 2012.

FERNÁNDEZ PEÑA, Carlos. «Sobre la ética sexual en el Liceo», Congreso Nacional de Enseñanza Secundaria, Santiago de Chile, 1912.

FÜRST NEUMANN, Ricardo. «El problema de la adolescencia de hoy », Boletín del Instituto Nacional, Año XXVI, nº66-67, Santiago de Chile, 1961.

GONZÁLEZ CANGAS, Yanko «Primeras culturas juveniles en Chile: pánico, malones, pololeo y matiné», Atenea, $\mathrm{n}^{\mathrm{0}} 503$, Concepción, (2011).

LOIS, Juan Serapio. «La comprensión bajo el aspecto pedagógico», Revista de Instrucción Secundaria, Tomo II, Santiago de Chile, 1891.

MAHAMUD, Kira. «Emociones y sentimientos: coordenadas históricas y multidisciplinares de un campo de estudio clave para las ciencias de la educación», Avances en supervisión educativa, nº 16, Madrid, 2012.

MARTIN, Jack \& McLELLAN, Anne-Marie. The education of selves: how psychology transformed students. New York: Oxford University Press, 2013 . 
MUÑOZ HERMOSILLA, José María. Historia elemental de la Pedagogía Chilena, Santiago de Chile: Editorial Minerva, 1918.

MUÑOZ HERMOSILLA, José María. Léxico Pedagógico. Santiago de Chile: Editorial Laguna Quevedo y Compañía, 1931.

PALMA, Octavio. «El profesor jefe de curso», Revista de Educación Secundaria, Año I, $\mathrm{n}^{0} 3$, Santiago de Chile, 1928.

PIGA, Arturo. La educación secundaria en Chile in Misión Educacional Chilena en Costa Rica. Informes y Trabajos. Volumen II. San José, Costa Rica: Editorial Borrasé Hermanos, 1939.

PLAMPER, Jan. The history of emotions. An introduction. Londres: Oxford University Press, 2012.

RAMÍREZ, Francisco O. y MEYER John W. Los currículos nacionales: modelos mundiales y legados históricos nacionales in CARUSO, Marcelo y TENORTH, Heinz-Elmar (compiladores) Internacionalización. Políticas educativas y reflexión pedagógica en un medio global. Buenos Aires: Granica, 2012.

REAL ACADEMIA DE LA LENGUA. Diccionario de la Lengua Castellana.

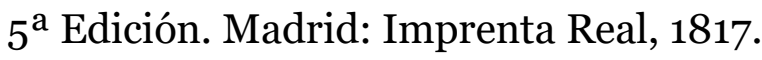

REYES, Judas Tadeo. Elementos de Moral y Política en forma de Catecismo Filosófico Cristiano para Enseñanza del Pueblo, y de los niños de las Escuelas de Santiago de Chile. Lima: Imprenta de Tadeo López, 1816 [ Editado por Cristián Guerrero Lira, en Cuadernos de Historia, $\mathrm{n}^{\mathrm{0}} 33$, 2000, Santiago de Chile]

ROSENWEIN, Barbara H. «Worrying about Emotions in History», The American Historical Review, volumen 107, n⿳0 ${ }^{\mathrm{O}}$, Chicago, 2002.

ROSSIG, Eduardo. Manual de Práctica Escolar. Santiago: Imprenta y Litografía Roma, 1896.

SENNETT, Richard. La Autoridad. Madrid: Alianza, 1982.

SERRANO, Sol, PONCE DE LEÓN, Macarena \& RENGIFO, Macarena. Historia de la Educación en Chile (1810-2010). Tomo I. Aprender a leer y escribir (1810-1880). Santiago: Taurus, 2012.

SOBE, Noah. «Researching emotion and affect in the history of education», History of Education: Journal of the History of Education Society, volumen 41, $\mathrm{n}^{\circ} 5$, Londres, 2012. 


\section{TRÖHLER, Daniel. Los lenguajes de la educación. Los legados} protestantes en la pedagogización del mundo, las identidades nacionales y las aspiraciones globales. Madrid: Octaedro, 2013.

TORO-BLANCO, Pablo. "Close to you: building tutorials relationships at the Liceo in Chile in the long 19th century", Jahrbuch für Historische Bildungsforschung, band 18, Berlín, 2012.

VELASCO, Toribio. «El recreo escolar. Maestros adustos y maestros joviales», Revista Pedagógica, Año II, $\mathrm{n}^{\circ}$ 4, Santiago de Chile, 1903.

PABLO TORO-BLANCO é Doutor em Historia (Pontifícia Universidade Católica do Chile, 2007). Magister em Historia (Universidade do Chile, 2002). Académico do Departamento de História da Universidade Alberto Hurtado. As linhas de investigação correspondem a história da educação e dos Movimentos estudantis no Chile e história das emoções.

E-mail: ptoro@uahurtado.cl

(b) http://orcid.org/0000-0001-8754-5692

Recebido em: 11 de dezembro de 2018

Aprovado em: 08 de julho de 2019 